\title{
LA CRISIS DEMOGRÁFICA DEL SIGLO XVI EN LOS ANDES: UNA DISCUSIÓN ACERCA DE SUS DIMENSIONES Y CONSECUENCIAS
}

\author{
THE DEMOGRAPHIC CRISIS OF THE 16TH CENTURY IN THE ANDES: \\ A DISCUSSION ABOUT ITS DIMENSIONS AND CONSEQUENCES
}

\author{
Carlos Contreras Carranza*
}

\begin{abstract}
El asentamiento español en el área andina en el siglo XVI determinó una grave crisis demográfica de la población indígena (tal como ocurrió con la irrupción europea en toda América). La debacle de esta alcanzó magnitudes elevadas, llevando a que la historiografía aluda a ella con términos como "catástrofe", "cataclismo", "derrumbe" o "colapso". Sus efectos se percibieron mucho más allá del período de "la conquista" o "asentamiento", extendiéndose a lo largo de todo el período colonial e influyendo decisivamente en la organización económica y política de largo plazo erigida en la región andina. En este artículo proponemos una discusión sobre la magnitud de la población aborigen en el momento del arribo europeo y la cronología de su debacle. Finalmente, reflexionamos acerca de sus consecuencias económicas para el Perú. Sin duda ella cambió el rumbo de la organización económica del país, al volver abundante la tierra y escaso el trabajo y convertir a quienes disfrutaban de este en perceptores de importantes rentas; asimismo, obligó a replantear una economía que, en principio, se había organizado para captar el excedente económico de la población conquistada por la vía del tributo.
\end{abstract}

Palabras claves: Crisis demográfica, siglo XVI, Perú.

The Spanish settlement in the Andean area in the sixteenth century determined a serious demographic crisis of the indigenous population (as happened with the European eruption in the Americas). The debacle of this one reached high magnitudes, taking to that the historiography refers to her with terms like "catastrophe", "cataclysm", or "collapse". Its effects were felt well beyond the period of "the conquest" or "settlement," extending throughout the colonial period and decisively influencing the long-term economic and political organization erected in the Andean region. In this article we propose a discussion about the magnitude of the aboriginal population at the time of European arrival and the chronology of its debacle. Finally, we reflect on its economic consequences for Peru. Without a doubt, she changed the course of the country's economic organization, since the land became abundant and work was scarce, and those who enjoyed it became recipients of important rents; also, forced to rethink an economy that, in principle, had been organized to capture the economic surplus of the population conquered by the way of tribute.

Key words: Demographic crisis, XVIth century, Perú.

El declive demográfico americano ocurrido a raíz de la invasión europea fue uno de los acontecimientos importantes de la historia del último milenio, como por la magnitud de la población desaparecida, cuanto por las consecuencias económicas y políticas que, para la historia americana, implicó el drástico cambio en las cantidades relativas de tierra y trabajo. Las cifras de la declinación han sido motivo de una larga controversia. Se conocen con cierta precisión los datos de la población indígena subsistente para fechas ubicadas a medio o un siglo después del arribo europeo, pero no la cantidad de población inicial, cuyo cálculo ha desatado una amplia especulación. La distancia que media entre los ocho y medio millones propuestos por Alfred Kroeber, y los ciento doce millones sugeridos por Henry Dobins, nos da una rápida idea de la poca claridad y consenso en este debate ${ }^{1}$.

En las últimas décadas ha habido esfuerzos por llegar a estimaciones más robustas y diferenciadas regionalmente, a fin de dimensionar con alguna precisión el cambio que en la disposición de tierra y trabajo fue ocurriendo en las diferentes áreas de la economía americana tras el asentamiento europeo $^{2}$. Conocer la tendencia demográfica (ascendente o descendente) de una sociedad, resulta un dato siempre interesante, ya que ella determinará el tipo de presiones que su organización afrontará para encarar dicha variación. En este artículo me propongo discutir cuál fue el tamaño de la población del Perú y del imperio inca en el

\footnotetext{
* Pontificia Universidad Católica del Perú. Departamento de Economía. Correo electrónico: ccontre @ pucp.edu.pe. Dirección postal: Av. Universitaria 1801, Lima 32, Perú.
} 
momento del contacto con la hueste conquistadora, y cuál la cronología de lo que hasta ahora ha sido descrito como una "catástrofe" o "colapso" demográfico ${ }^{3}$. El territorio del Perú actual era la parte más densamente poblada del imperio inca, conteniendo a unos dos tercios de todo el reino del Tahuantinsuyo, según el cálculo de diversos historiadores como Rosenblat (1954), Wachtel (1976) y Pease (1991). Mi planteamiento es que las cifras de nueve millones (para el Perú) y once a quince (para el imperio) que actualmente se manejan, están sobredimensionadas, al exagerar la despoblación ocurrida durante el período inicial del asentamiento español, conocido como pre toledano (1532-1570).

En la sección que sigue hacemos una crónica de las propuestas lanzadas acerca del tamaño demográfico de los Andes centrales en el primer tercio del siglo XVI, para luego aportar la nuestra, que reduce a menos de una tercera parte el dato hasta ahora dominante. Seguidamente, discutimos la cronología de la disminución y señalamos algunas consecuencias de la debacle demográfica del siglo XVI en los Andes; la que, aunque estimamos más moderada que otros autores, de ninguna manera negamos.

\section{La población del imperio Inca en vísperas del arribo europeo}

Los primeros investigadores que, sobre la base de la consulta de fuentes del siglo de la conquista y con el uso de procedimientos explícitos, calcularon el tamaño de la población del imperio Inca fueron historiadores norteamericanos como John Rowe y George Kubler, comprometidos en los estudios de las "áreas culturales" americanas ${ }^{4}$. En 1946 propusieron cifras de 6 millones y 3.4 millones de habitantes, respectivamente, para todo el imperio inca, que eran bastante más bajas que los datos de diez a quince millones que hasta entonces habían referido diversos ensayistas y observadores (véase Cuadro 1$)^{5}$.

La tesis de Noble David Cook, presentada en la Universidad de Texas en 1973 y convertida en libro en 1981 por la Cambridge University Press (CUP), marcó un hito importante en el debate sobre la población inca, dada la rigurosidad de su esfuerzo y el prestigio de la academia norteamericana. Cook había sido entrenado en la "Escuela de California" de Sherburne Cook y Woodrow Borah, quienes habían reconstruido la historia demográfica de México en el tiempo de la conquista. Tres décadas después apareció la versión en castellano, enriquecida con un nuevo prefacio del autor y un apéndice con los datos de población que habían sido el soporte de su trabajo. N. D. Cook (2010: 165) propuso la cifra de 9 millones como población de la sección del imperio incaico que correspondería a los confines del Perú actual, con unos parámetros de variación fijados entre los 5.5 y los 9.4 millones como límites mínimo y máximo. No arriesgó una cifra para todo el Tahuantinsuyo, pero aplicando las cifras de los más contenidos de

Cuadro 1: Estimaciones de la población del Imperio Inca en el momento de la Conquista española.

\begin{tabular}{lc}
\hline Autores y año de la estimación & Población en millones \\
\hline A. Carrió de la Bandera, 1773 & 7 \\
S. Lorente, 1860 & 10 \\
R. Cappa, 1888 & 4 \\
M. V. Sapper, 1924 (en Baudin 1943) & $12-15$ \\
P. Means, 1932 & 24 \\
J. Rowe, 1946 & 6 \\
G. Kubler, 1946 & 3,4 \\
A. Rosenblat, 1954 & 3,3 \\
L. E. Valcárcel, 1959 & $13-15$ \\
H. Dobyns, 1966 & $30-37,5$ \\
C. T. Smith, 1970 & 12 \\
N. Wachtel, 1971 & 10 \\
N. D. Cook, 1981 & (solo Perú actual) 9 \\
\hline
\end{tabular}


sus colegas, como Ángel Rosenblat, ello habría un supuesto un añadido de 1.5 a 2 millones; o sea un total de once millones de habitantes.

La tesis de Cook analizó el lapso corrido entre el recuento organizado por el virrey Francisco de Toledo, en los inicios de la década de 1570, y las cifras del Compendio de Antonio Vázquez de Espinoza (1948), que, aunque fechadas en 1630, correspondían a recuentos realizados entre 1600 y $1620^{6}$. Sobre esta base fijó en 1.29 millones la población indígena subsistente c. 1570, y en 0.6 millones la subsistente c. 1620. Estas cifras resultaban, en parte, de la proyección del cambio en el número de tributarios (los indígenas varones entre 18 y 50 años) que, entre las mismas fechas, habría caído de 261 mil a $136 \mathrm{mil}^{7}$. Este fue el resultado más sólido, el núcleo duro de su trabajo, que demostró, así, sobre la base de los datos aportados por los propios recuentos demográficos virreinales, que a lo largo del último cuarto del siglo XVI y las primeras décadas de la centuria siguiente hubo una caída de la población nativa del orden de un 50 por ciento.

Demographic Collapse, el libro de Cook, aportó, además, una geografía de la crisis de la población andina: las regiones de la costa sufrieron el golpe más duro, viendo reducirse su población a aproximadamente una tercia parte en el medio siglo corrido entre 1570 y 1620 , mientras las regiones de sierra se defendieron mejor, salvo en el caso del norte, cuyo desempeño se aproximó al resultado de la costa. Tanto la sierra central como la sierra sur consiguieron conservar un $60 \%$ de sus efectivos (p. 171). Como los españoles ingresaron al Perú por el norte y por la costa, podríamos decir que mientras más lejos estuvieron los nativos de dicho lugar de ingreso, tanto mejor pudieron defenderse de la devastación demográfica.

La geografía de la crisis trazada por Cook es sustentada con varias razones concurrentes: el clima cálido y húmedo de la costa y el hecho de que la población en esta región se agrupaba para vivir en valles de alta densidad demográfica, favoreció la propagación de epidemias. Para el autor las epidemias traídas por los españoles y desconocidas por los nativos, fueron la causa principal de la crisis demográfica. La hueste de conquistadores se asentó primero en la costa, donde para 1535 , apenas tres años después de su ingreso al Perú, ya habían fundado las ciudades de Piura, Trujillo y Lima. Por contraste, el clima frío y seco de la región serrana, junto con la mayor dispersión de su población, volvieron más lento el avance de las epidemias en su territorio.

El planteamiento que hicieron a Cook los editores de la CUP para publicar la tesis, a condición de que incorporase el dato de la población autóctona en vísperas de la conquista, animaron al autor, según sus propias palabras, a "hacer algo casi imposible: calcular la población indígena en tiempos de los incas, el tema que interesaba a todos" (p. 17). Para ello extrapoló hacia atrás la tasa de despoblación obtenida para el lapso de 1570-1620. Si la población de 1570 se había desplomado a la mitad para 1620 , podríamos suponer que la de 1570 fue, a su vez, el doble de la de 1520. El resultado era una población de 2.74 millones para 1530, la víspera del arribo de la hueste de Pizarro. Sin embargo, las bacterias portadoras de los virus arribaron a las costas peruanas antes que los europeos: alrededor de los años 15241526, al punto que el inca Huayna Capac habría perecido precisamente por causa de la viruela. Cook retrotrajo, entonces, hasta 1520 el momento de máxima población del imperio inca que, aplicando la misma tasa de despoblación del lapso 1570-1620, resultó en 3.3 millones de habitantes (p. 146). ${ }^{8}$ Esta era la misma cifra que tanto Kubler como Rosenblat habían propuesto décadas atrás.

Cook, sin embargo, juzgó que las condiciones en que se desenvolvió la población nativa en el "período pre-toledano", fueron peores que en las de la fase 1570-1620, por haber coincidido con la guerra de conquista, las exploraciones hacia las regiones periféricas del Tahuantinsuyo, las luchas intestinas entre los conquistadores y las de los encomenderos contra la corona española. A ello debía añadirse que las epidemias debieron resultar más virulentas entre una población virgen al contacto de las nuevas bacterias, que entre una que ya convivió cierto período con ellas. En palabras de Cook (2010: 164):

"No estoy convencido en absoluto de que la tasa de mortandad entre 1520 y 1570 solamente haya sido igual a la del siguiente medio siglo. La era toledana y postoledana se caracterizaron por relaciones formalizadas pero abiertamente estables entre las razas. No hubo grandes alzamientos o guerras sangrientas de exterminio entre los recién llegados y los 
nativos, excepción hecha de la resistencia localizada y la ejecución final de Túpac Amaru I y sus compañeros".

¿Cuánto más graves fueron las condiciones de vida para la población nativa antes de 1570 ? Cook propuso que el doble de graves, y optó por duplicar la tasa de la despoblación indígena hallada para el lapso 1570-1620, para el período anterior, de 1520-1570. Obtuvo la cifra de 8.87 millones de habitantes para 1520 , que fue redondeada a nueve millones (pp. 147-148).

Los datos demográficos parciales existentes para fechas del período pre-toledano, reunidos por el propio Cook, no le parecieron dignos de confianza como para ajustar dicho número. Sobre la base de ellos, llegó a un estimado de solo 3.11 millones para 1520 , pero arguyó que: "esta proyección es más baja de lo que la población probablemente fue" (p. 149). Era el tiempo de los números altos; cuando se hablaba de 25 millones para el México central de vísperas de la invasión española; hoy, que dicha cifra ha caído hasta la mitad, o aún menos, los tres millones y quizás algo más, para el imperio inca, pasarían por una cifra razonable ${ }^{9}$.

Aunque los argumentos de Cook y otros historiadores y demógrafos, como Carlos S. Assadourian (1985 y 1989) y Massimo Livi Bacci (2006-a y 2006b), para explicar que durante el lapso pre-toledano la mortalidad indígena debió haber sido sensiblemente mayor que en la época siguiente, son plausibles, podríamos mencionar hechos que apuntarían en una dirección opues$\mathrm{ta}^{10}$. Primero, que el número de españoles antes de 1560 fue mínimo y se dispersaron poco fuera de las poblaciones que fundaron ${ }^{11}$. Las posibilidades de diseminación de bacterias y enfermedades desconocidas habrían sido más reducidas que en la época posterior, cuando el número de no indios (incluyendo a los esclavos africanos, que habrían traído su propio equipaje de virus) aumentó significativamente.

Segundo, que la "desestructuración" de la economía y sociedad andina fue hasta 1570 todavía débil. Los trabajos de John V. Murra (2002) y el propio Assadourian (1994) enfatizaron que hasta 1570 predominó una "economía de renta", en la que el excedente económico era obtenido, básicamente, por el modo de producción indígena, del que se apropiaban los conquistadores españoles mediante el tributo de la encomienda ${ }^{12}$. El nivel local e intermedio de las jefaturas étnicas no se había quebrado: los curacas seguían organizando la producción y el consumo agropecuario ${ }^{13}$. Las reformas toledanas, en cambio, desarticularon el modo indígena, al reorganizar a la población en nuevos pueblos, socavar el poder de las jefaturas locales insertando nuevas autoridades, introducir el trabajo forzado de los indios en las minas y monetizar el tributo ${ }^{14}$. Massimo Livi (2006b: 193-230) destaca el hecho de que la capacidad de recuperación demográfica de la sociedad indígena andina fue inhibida por la "desestructuración" que sufrió bajo los españoles. Pero el embate desestructurador ocurrió a partir de 1570, no antes.

Assadourian (1994: cap. 1) puso de relieve la crueldad y violencia con que actuó la hueste conquistadora en el Perú (comparada con lo ocurrido en México): pueblos enteros quemados con toda su población, expediciones de escarmiento cuando llegaban noticias del asesinato de un encomendero, y "rancheos" de las cosechas, que dejaron a los pueblos expuestos al hambre. Todo ello, sin embargo, remitió después de 1554, una vez debelados los levantamientos de Gonzalo Pizarro y Francisco Hernández Girón. Entre 1554 y la organización de las reducciones toledanas mediaron veinte años durante los cuales la población indígena debió haber desplegado su capacidad de recuperación.

\section{Los recuentos de población de la segunda mitad del siglo XVI}

Los primeros registros sistemados de la población nativa andina ocurrieron hacia los mediados del siglo XVI, cuando funcionarios designados por el Presidente de la Audiencia de Lima, Pedro de La Gasca, procedieron a la tasación de los tributos de la encomienda, en acatamiento de las disposiciones de la corona. Se conocen algunos datos de dicho registro para ciertos repartimientos, pero no se cuenta todavía con una información panorámica ${ }^{15}$. Lo más parecido a ello pero con datos poco desagregados es el documento conocido como el "Padrón de Avendaño", fechado en 1561. Posteriormente, el virrey Francisco de Toledo procedió a un nuevo registro, realizado en lo fundamental entre 1571-1575, cuyos resultados se han conservado mejor que los de La Gasca, y han sido publicados en parte por N. D. Cook (1975) y 
Ronald Escobedo (1979), entre otros autores ${ }^{16}$. Al comenzar la última década del siglo XVI el virrey Hurtado de Mendoza encargó una nueva Relación del número de tributarios, que fue el cuadro de Luis Morales de Figueroa, fechado en 1591. Este funcionario repitió en parte las cifras del censo de Toledo, pero presentó también nuevas cifras en el caso de las provincias donde se había actualizado los datos a raíz de visitas o retasas ${ }^{17}$.

El número de tributarios se mantiene relativamente estable en el lapso de treinta años corridos entre el primer y último recuento, como veremos en los siguientes cuadros. No es lo que se esperaría en un contexto de derrumbe demográfico. Pedro de Avendaño era Secretario de Cámara de la Audiencia de Lima cuando fue comisionado para consolidar las cifras sobre población tributaria y monto del tributo en el virreinato (Escobedo 1979: 50). Reunió las cifras recogidas por los visitadores de La Gasca, reemplazándolas, cuando correspondía, por las retasas o recuentos hechos posteriormente y compuso el cuadro que puede verse abajo (Cuadro 2). Para toda el área del Tahuantinsuyo su Padrón arrojó una población de
$1.787,035$ indios, de los que 408,287 eran tributarios entre los 16 y 50 años ${ }^{18}$. Es el primer cuadro completo de la población indígena peruana después del arribo español, incluyendo las regiones de Quito y el Alto Perú, hoy correspondientes a las república de Ecuador y Bolivia, respectivamente.

Los datos van agrupados según las provincias gobernadas por las ciudades fundadas por los españoles. Se anota que de las de Jaén, Santiago de los Valles, Zamora, Santa Cruz y Tucumán "no se ha sacado [datos], porque están por tasar" (Matienzo 1967: 109). No se trataba de regiones muy pobladas, salvo, probablemente, la última; entre todas podrían haber aportado un máximo de cien mil pobladores ${ }^{19}$. En la edición que Guillermo Lohmann hizo del libro de Matienzo al cumplirse los cuatrocientos años de su "Gobierno del Perú", añadió los datos de Jauja y Zamora, que pudo localizar como parte de esta información, los que hemos incluido en el cuadro. El peso del tributo era desigual en el virreinato, oscilando entre los 5.58 pesos anuales de Piura y los 1.32 pesos de Quito. El promedio era de tres pesos por tributario.

Cuadro 2. Población indígena en el Perú, de acuerdo al Padrón de Pedro de Avendaño de 1561.

\begin{tabular}{lccccc}
\hline Provincias & $\begin{array}{c}\text { Población indígena } \\
\text { total }\end{array}$ & $\begin{array}{c}\text { Tributarios entre } \\
16-50 \text { años }\end{array}$ & $\begin{array}{c}\text { \% de tributarios } \\
\text { sobre la población } \\
\text { total }\end{array}$ & $\begin{array}{c}\text { Valor anual de los } \\
\text { tributos (en pesos) }\end{array}$ & $\begin{array}{c}\text { Tributo por } \\
\text { tributario (pesos) }\end{array}$ \\
\hline Cuzco & 267,000 & 78,000 & 29.2 & 377,000 & 4.83 \\
La Plata & 232,800 & 46,560 & 20.0 & 178,850 & 3.84 \\
La Paz & 150,655 & 30,131 & 20.0 & 150,600 & 5.00 \\
Arequipa & 201,830 & 40,366 & 20.0 & 93,700 & 2.32 \\
Los Reyes & 99,600 & 25,577 & 25.7 & 55,600 & 2.17 \\
Huamanga & 112,520 & 22,504 & 20.0 & 65,914 & 2.93 \\
Truxillo & 215,000 & 42,000 & 19.5 & 63,800 & 1.52 \\
Guánuco & 118,470 & 23,506 & 19.8 & 55,600 & 2.37 \\
Quito & 240,670 & 49,134 & 20.4 & 64,800 & 1.32 \\
San Miguel (de Piura) & 16,617 & 6,054 & 36.4 & 33,800 & 5.58 \\
Puerto Viejo & 2,297 & 1,377 & 59.9 & 5,952 & 4.32 \\
Guayaquil & 4,742 & 2,280 & 48.1 & 12,664 & 5.55 \\
Loxa & 9,495 & 3,647 & 38.4 & 11,004 & 3.02 \\
Chachapoyas & 58,397 & 16,309 & 27.9 & 27,600 & 1.69 \\
Jauja & 17,248 & 5,328 & 30.9 & 12,242 & 2.30 \\
Zamora & 11,222 & 6,093 & 54.3 & 19,000 & 3.12 \\
Todo el Perú & $1.787,035$ & 408,287 & 22.8 & $1.257,918$ & 3.08 \\
\hline
\end{tabular}

${ }^{\circ}$ Con la exclusión de Jaén, Santiago de los Valles, Santa Cruz y Tucumán.

Fuente: Juan de Matienzo (1967), p. 109. 
Añadiendo la población de las provincias no consideradas en el recuento y contando con algún margen de omisión tendríamos una cifra de aproximadamente dos millones de indígenas para la década de 1550 en todo el virreinato. Si descontamos del cuadro las cifras correspondientes a las regiones que no están comprendidas dentro del Perú actual, como Quito, Guayaquil, Loja, La Paz y La Plata, quedaríamos con una población indígena de 1.164,434 y una de tributarios de 269,336, para una fecha promedio de $1555^{20}$. Matienzo (1967: 99) proporcionó una cifra mayor de tributarios y de población total, basándose en la misma fuente:

\section{"[...] porque según la Visita que se hizo -año de 1560 años [sic] hasta el de 1561-, había hasta allí quinientos treinta y cinco mil indios tributarios, y cinco tantos que no eran tributarios, y rentan cada año un millón y ciento cuarenta y siete mil y ciento sesenta pesos, [...]”.}

Lo único menor en estas cifras fue la renta del tributo, de la que había dar cuenta a la corona. Aparte de los tributarios, para Matienzo había cinco veces el número de estos, con lo que la población indígena total superaría los tres millones $^{21}$. Matienzo fue un conocido defensor de los intereses de los encomenderos ${ }^{22}$. Como a estos se les había acusado de ser los culpables de la disminución de los indios, tal vez proporcionó cifras exageradas de su número; por otro lado, un abultado número de tributarios llevaría a las autoridades a suponer un monto elevado de tributo, moviéndolas a exigir un mayor aporte fiscal a los encomenderos, por lo que debía ser cuidadoso con las cifras. En todo caso, para él, eran los caciques indios los causantes de los malos tratamientos y las extorsiones contra los nativos; una idea en que le acompañaron otros observadores de la época, como Polo de Ondegardo y Pedro de Quiroga ${ }^{23}$.

Los datos de Matienzo se acercan bastante a los aportados por Cook para 1570, basados en el censo de Toledo: 1.290,680 de población indígena total y 260,554 de tributarios ${ }^{24}$. La población indígena total de 1555 aparece un poco menor a la de 1570, pero la de tributarios, al contrario, luce un poco mayor (véase Cuadro 3). Sin embargo, debe tenerse en cuenta que los datos de Avendaño incluyen como tributarios a los varones desde los
16 años, y no desde los 18 ; haciendo el ajuste pertinente los tributarios de 1555 serían algo menores a los de 1570. De acuerdo a los datos de la Visita de Toledo aportados por Ronald Escobedo, los tributarios dentro del espacio peruano actual sumarían 241,046, una discrepancia de $7 \%$ con los números de Cook ${ }^{25}$.

La "Relación del número de indios tributarios" de 1591 firmada por Luis Morales de Figueroa, encargado para esta tarea por el segundo Marqués de Cañete, virrey del Perú en ese entonces, entrega el dato de 325,899 tributarios (entre 18-50 años se entiende) y el monto anual de los tributos, pero no proporciona datos del total de la población. Cook (2010: 128-129) comprobó que para varios repartimientos los datos de Morales de Figueroa repetían los del censo de Toledo, por lo que consideró que su cifra total estaría sobreestimando los datos de población, puesto que en los casos en que se hicieron retasas se comprobó que la población había disminuido. Pero bajo ese argumento, correspondería, asimismo, pensar que en los repartimientos donde no se realizaron retasas, no hubo solicitudes para hacerlas porque la población no había sufrido menoscabo y podían afrontar el pago del tributo fijado por Toledo $^{26}$. No deberíamos, entonces, despreciar estos datos, que van consignados en el siguiente cuadro (Cuadro 3), comparándolos con los de 1561 (debemos recordar, no obstante, que aunque los recuentos llevan estas fechas, corresponden seguramente a algunos años antes (un promedio de 1555, para el caso del Padrón de Avendaño, 1585 para la Relación de Morales de Figueroa) y 1573 (visita de Toledo).

Las diferencias en el número de tributarios entre los tres recuentos parecen obedecer, más que a cambios en el tamaño de la población, al hecho de que no contienen datos para las mismas provincias (por ejemplo, en el recuento de Toledo no hay datos sobre Quito, Cuenca, Loja y Zamora, ni tampoco Chachapoyas) o no comprenden el mismo rango de edad para los tributarios. De todos modos, se hace evidente una disminución entre el registro de " 1561 " y el de Toledo, que se hace marcado en el caso de la región del norte: las provincias de Piura, Trujillo y Huánuco, que perdieron en ese lapso de casi veinte años, el $42 \%, 28 \%$ y $23 \%$, respectivamente de sus tributarios. En el sur, únicamente Arequipa y Charcas (que perdieron, ambas, el 32\% de tributarios) registraron disminuciones importantes. 
Cuadro 3. Población indígena tributaria y tasas del tributo en el Perú, 1561, 1573 y 1591.

\begin{tabular}{|c|c|c|c|c|c|c|c|}
\hline Provincias & $\begin{array}{c}\text { Tributarios en } \\
1561\end{array}$ & $\begin{array}{c}\text { Tributarios en } \\
1573\end{array}$ & $\begin{array}{c}\text { Tributarios en } \\
1591\end{array}$ & $\begin{array}{l}\text { Tributo anual en } \\
1561 \text { (pesos) }\end{array}$ & $\begin{array}{l}\text { Tributo anual en } \\
1591 \text { (pesos) }\end{array}$ & $\begin{array}{l}\text { Tributo p.c. en } \\
1561 \text { (pesos y } \\
\text { décimos de peso) }\end{array}$ & $\begin{array}{l}\text { Tributo p.c. en } \\
1591 \text { (pesos y } \\
\text { décimos de peso) }\end{array}$ \\
\hline Piura & 6,054 & 3,537 & 3,537 & 33,800 & 12,890 & 5.6 & 3.6 \\
\hline Truxillo & 42,000 & 34,519 & 17,597 & 63,800 & 62,100 & 1.5 & 3.5 \\
\hline Jaén & n.d. & n.d. & 2,654 & n.d. & 7,980 & & 3.0 \\
\hline Chachapoyas & 16,309 & n.d. & 7,045 & 27,600 & 21,390 & 1.7 & 3.0 \\
\hline Moyobamba & n.d. & n.d. & 678 & n.d. & 2,290 & & 3.4 \\
\hline Huánuco & 23,506 & 18,047 & 18,089 & 55,650 & 65,180 & 2.4 & 3.6 \\
\hline Lima & $30,905^{\circ}$ & 30,711 & 30,708 & 67,842 & 119,920 & 2.2 & 3.9 \\
\hline Huamanga & 22,504 & 27,488 & 26,057 & 65,914 & 101,435 & 2.9 & 3.8 \\
\hline Cuzco & 78,000 & 77,056 & 74,977 & 377,000 & 380,835 & 4.8 & 5.1 \\
\hline Arequipa & 40,366 & 27,429 & 19,794 & 93,700 & 98,355 & 2.3 & 5.0 \\
\hline Chucuito & n.d. & 17,779 & 17,779 & n.d. & 80,000 & & 4.5 \\
\hline Quito & 49,134 & n.d. & 24,380 & 64,800 & 79,235 & 1.3 & 3.2 \\
\hline Cuenca & n.d. & n.d. & 10,037 & n.d. & 50,185 & & 5.0 \\
\hline Loja & 3,647 & n.d. & 2,849 & 11,004 & 9,260 & 3.0 & 3.3 \\
\hline Zamora & 6,093 & n.d. & 6,762 & 19,000 & 33,810 & 3.1 & 5.0 \\
\hline Guayaquil & 2,280 & 2,198 & 2,198 & 12,664 & 8,515 & 5.6 & 3.9 \\
\hline Puerto Viejo & 1,377 & 1,253 & 1,253 & 5,952 & 4,610 & 4.3 & 3.7 \\
\hline $\mathrm{La} \mathrm{Paz}$ & 30,131 & 26,432 & 27,837 & 150,600 & 177,910 & 5.0 & 6.4 \\
\hline Charcas & 46,560 & 31,776 & 31,671 & 178,850 & 191,410 & 3.8 & 6.0 \\
\hline Total & 396,866 & 298,225 & 325,899 & $1,257,918$ & $1,506,290$ & 3.2 & 4.6 \\
\hline
\end{tabular}

${ }^{\circ}$ Hemos añadido a Lima los datos de Jauja entregados por Lohmann, como parte del mismo recuento.

Fuentes: Para 1561: Matienzo, 1967: 109-110. Para 1573: R. Escobedo, 1979: 210-264.27 Para 1591: Zavala, 1978-79, I: 185.

Huamanga es la única provincia que muestra un incremento digno de reseña: $22 \%$, mientras Lima y Cuzco muestran estabilidad. Retirando las cifras correspondientes a la Audiencia de Quito (a fin de poder hacer comparables los dos registros), la caída en el número de tributarios entre 1555-1573 (fechas promedio de ambos registros) sería, en cifras redondas, de 340 mil a 298 mil; equivalente a un retroceso de 0.7 anual, y a prácticamente nada si restamos un $10 \%$ de tributarios en el censo de $\mathrm{La}$ Gasca, a fin de apartar a los tributarios de 16 y 17 años. En cifras globales el número de tributarios se habría mantenido constante entre los censos de $\mathrm{La}$ Gasca y Toledo.

El registro de 1591, que sí es comparable en comprensión territorial con el de Avendaño, abarcando todo el virreinato peruano menos las zonas del norte argentino, reporta una disminución en el número de tributarios para el lapso 1555-1585, de $0.3 \%$ anual, una vez hecho el ajuste en el recuento de Avendaño por la diferencia en el rango de edad. Trujillo representa el caso más dramático de caída (los tributarios retroceden 58\%) y Arequipa muestra, asimismo, una reducción significativa (28\%). Lima, Huamanga y Cuzco continuaron mostrando básicamente estabilidad. Retirando del cuadro de 1591 las provincias no pertenecientes al Perú actual, quedan unos 225 mil tributarios, un número menor que los $241 \mathrm{mil}$ del tiempo de Toledo. El ritmo de la caída ( $0.6 \%$ anual, considerando un lapso de doce años: 1573-1585) resulta, en cualquier caso, inferior a las cifras propuestas por Cook (2010: 147) para el ciclo 1570-1600, que van entre los extremos de $-3.8 \%$ en la costa sur y $-1.2 \%$ en la sierra central y sur. Por otro lado, la carga del tributo se volvió más gravosa entre 1561 y 1591 , al pasar de 3.2 pesos anuales a 4.6 pesos, pero con una menor dispersión en cuanto al monto, que ahora tenía como extremos tasas de tres pesos en regiones del norte como Jaén o Chachapoyas, y seis pesos o poco más, en el Alto Perú (Charcas y La Paz) ${ }^{28}$. 
La proximidad en el número de tributarios para distintas fechas entre 1555 y 1585 , se explicaría porque, tras la crisis inicial, anterior a 1555 , la población indígena venía estabilizándose. El planteamiento de Cook, de que a los funcionarios de la década de 1550 se les habrían escapado muchos indios, -por lo que contendrían los datos de Avendaño una sub numeración de la población indígena, y los de Morales de Figueroa, al contrario, una sobre numeración, por repetir las cifras de Toledo-, resulta desestimada por testimonios como el de Polo de Ondegardo. De acuerdo a este experimentado funcionario, los visitadores conocían las mañas de los caciques para ocultar a sus indios, y realizaban sus correcciones:

\begin{abstract}
"Luego que las vissitas [de Las Gasca] se empezaron, como a los caciques se dio a entender la causa porque se hazían, empezaron a usar (para el efecto de encubrir los yndios) de los remedios que agora hacen para encubrir el número, escondiéndolos y asolando los pueblos" (Polo 2013: 310, párrafo 658).
\end{abstract}

Esta tendencia al ocultamiento de los pobladores se practicaba, de acuerdo a Polo, desde el gobierno de Francisco Pizarro:

\begin{abstract}
"De manera que siempre se entendía que mil yndios de visita eran mil e quinientos de número. Pero juntas las unas vissitas con las otras y con la consideración del que tracta de ello, en quanto al número [que informan los documentos] puede aver poco hierro" (Polo 2013: 312, párrafo 669 ).
\end{abstract}

¿Hicieron los autores de los recuentos "la consideración" que menciona Polo, confrontando unas visitas con otras y añadiendo dicha proporción de omisos? No podemos estar seguros de momento.

Mientras no aparezcan mejores fuentes para los años en que el Padrón de Avendaño y la Relación de Morales de Figueroa nos proveen de cifras, no cabe desdeñarlas. Ciertamente se trata de números poco desagregados y con algunos redondeos que revelarían la falta de datos precisos (en el caso del Padrón de Avendaño), o que repiten (en el de Morales de Figueroa) los resultados del censo de Toledo. Pero parece que los autores de los recuentos sabían lo que hacían y procuraron exhibir un cuadro lo más exacto posible de la realidad demográfica indígena. Sus cifras dejan la conclusión de que después de la crisis inicial de 1532-1555, advino una época de estabilidad ${ }^{29}$.

\section{La crisis demográfica a través de la masculinidad y la distribución de edades}

Después de la publicación del libro de Cook, María Rostworowski y Pilar Remy (1992) editaron una Visita de la provincia de Cajamarca, en la sierra norte peruana, realizada en dos momentos: 15711572 y 1578. Fue un aporte importante porque en los recuentos de Toledo estaba ausente precisamente la zona norte. La Visita comprende básicamente los pueblos de la encomienda de Melchor Verdugo. Los datos resultantes, alineados con la información con que se cuenta para años anteriores resultan sorprendentes (véase Cuadro 4).

Inesperadamente, la cifra de tributarios crece entre 1540 y 1567. Pilar Remy explica, sin embargo, que en 1540 no ocurrió una Visita propiamente, sino que el número de tributarios fue aportado por los caciques reunidos en Cajamarca por el encomendero, que probablemente disminuyeron el número real ${ }^{30}$. De todos modos, no parece haber ocurrido una caída tan grande en dicho lapso, a pesar de que nos encontramos en la años más duros de la crisis demográfica, y en la región norte, en la que según Wachtel y Cook, la crisis fue más grave que en el sur. En los años posteriores a 1567 sí habría ocurrido una caída de los tributarios, aunque más bien leve si tomamos en cuenta el añadido de los tributarios recién contados en 1578 (omitidos en el recuento de 1571-1572) $)^{31}$.

Cuadro 4. Población indígena tributaria en Cajamarca, $1540-1571 / 1578$.

\begin{tabular}{cc}
\hline Años & Tributarios de $20-50$ años \\
\hline 1540 & 3493 \\
1567 & 5169 \\
$1571-72$ & $4268(5008)^{\circ}$ \\
\hline
\end{tabular}

- La cifra de 5008 resulta añadiendo a los datos de la Visita de 1571-1572, 740 tributarios que no fueron contados en aquella ocasión por pertenecer a pueblos que no alcanzaron a ser visitados, pero que sí lo fueron seis años más tarde, en 1578. Fuente: Rostworowski y Remy, 1992: 52 y ss. 
El caso del corregimiento o provincia de Conchucos (también en la sierra norte) se asemeja al de Cajamarca, en el sentido de mostrar una caída suave del número de tributarios en el siglo XVI. En este caso, los 5850 tributarios de 1548 (Visita de La Gasca) disminuyeron a 5113 en 1575 (una velocidad de caída de $0.5 \%$ anual) y a 4359 en 1593/94 (una velocidad de caída de $0.9 \%$ anual, y de $0.65 \%$, si consideramos todo el ciclo 1548-1593 ${ }^{32}$. Aparte de tratarse de una diminución más paulatina de lo que las cifras de la "catástrofe demográfica" señalaron, es interesante ver que, en este caso, ella se acentuó en el segmento más tardío del siglo XVI.

Los datos de la Visita de Cajamarca impresionan por el tamaño que sobre el total demográfico tuvieron los jóvenes menores de 20 años. Fueron un $47.8 \%$, que nos revela una población en franca recuperación. La baja masculinidad (91.5 hombres por cada cien mujeres), notoria especialmente entre los mayores de cincuenta (donde llega a ser de apenas 63 por cada cien mujeres), transmite la huella de la crisis demográfica de la conquista. Para el período postoledano un caso diferente sería el de la provincia de Andahuaylas, en la sierra sur, para el que se registraron 5330 tributarios en la Visita de Toledo (año de 1571), 3130 en una revisita efectuada en 1604 y solo 1751 en $1630^{33}$. Sin duda, una severa caída demográfica (-1.9\% anual entre 1571-1620). Semejante es el caso de las nueve provincias de la sierra central designadas para proveer de mitayos a las minas de Huancavelica. De acuerdo al contador del Tribunal de Cuentas, López de Caravantes (1985, IV: 207-209), cuando se entabló la mita disponían de 69 mil "y tantos" tributarios, mientras que para 1629 , quedaban solo 25 mil y tantos; una caída de 1,8\% anual en el lapso 1573-1629. La provincia de Chucuito, en el sur, representa el caso de las provincias que, gracias a las Visitas encontradas, permiten reconstruir su evolución demográfica desde las fechas tempranas de la Conquista: en 1532 contaba con 20,270 tributarios, que se transformaron en 18,032 en 1549, 15,404 en 1567, 17,779 en 1573 y 13,364 en 1613 ; es decir, una caída con altibajos y más bien pausada $(-0.5 \%$ anual entre 1532-1613) ${ }^{34}$.

La Visita de Toledo clasificó a la población indígena según su sexo y, en el caso de los hombres, de acuerdo a grupos de edad divididos entre los que: a. tenían una edad menor a la indicada para tributar (18 años), b. tenían una edad tributaria (entre 18 y 50 años) y c. ya habían superado la edad del tributo (mayores de 50 años). La comparación de los tamaños relativos de estos grupos con su distribución en otros momentos de la historia peruana pone de relieve la crisis demográfica acontecida en los mediados del siglo XVI (véase Cuadro 5).

La crisis demográfica del siglo XVI se manifiesta sobre todo en el bajo número de varones en 1573, en comparación a los años posteriores. En 1793, 1876 y 1940 el país tuvo una mayoría masculina, mientras que en el censo del virrey Toledo la tasa de masculinidad fue de únicamente 93 varones por cada cien mujeres. El hecho de que la mortalidad se haya cebado en los varones, expresaría la importancia que la situación de guerra entre 1532-1554 (o incluso desde años anteriores, si consideramos los enfrentamientos

Cuadro 5. Distribución de la población indígena masculina peruana por grandes grupos de edad, ss. XVI-XX (cifras porcentuales).

\begin{tabular}{lccccc}
\hline & 1561 & 1573 & 1793 & 1876 & 1940 \\
\hline Varones/Población total & & 46.3 & 50.9 & 50.6 & 50.1 \\
Varones menores/Población total $^{\circ}$ & & 20.9 & & 22.5 & 26.6 \\
Varones viejos/Población total\# $^{\text {Varones adultos/Población total }^{\circ \circ}}$ & 22.6 & 20.6 & 22.8 & 22.5 & 18.2 \\
\hline
\end{tabular}

\footnotetext{
- Se considera como Menores, para 1573: a los menores de 18 años; para 1876 y 1940 a los menores de 20 años.

\# Se considera como Viejos, para 1573: a los mayores de 50 años; para 1876 y 1940 a los mayores de 49 años. ${ }^{\circ}$ Se considera como Adultos, para 1561: a los que tienen entre 16-50 años; para 1573 y 1793; a quienes tienen entre 18-50 años; para 1876 y 1940: a quienes tienen entre 20 y 49 años.

Fuentes: Para 1561; Matienzo 1967: 169; para 1573: Cook, ed, 1975; Para 1793: Unanue, 1793.
} 
entre huascaristas y atahualpistas) tuvo para la catástrofe demográfica. En cuanto a los grupos de edad, las brechas existentes son pequeñas y pueden atribuirse, fundamentalmente, a las diferencias entre los rangos de edad que hay entre los censos (en 1573 los menores corresponden a quienes suman menos de dieciocho años, mientras en 1876 y 1940 a los menores de 20 años). La excepción serían los más de dos puntos de brecha que se advierten entre el porcentaje de tributarios de 1573 y de 1793, que sí corresponden al mismo rango de edad ( 18 a 50 años). A menos que queramos suponer que los indios de la época de Toledo se ocultaban mejor del conteo que los de finales del siglo XVIII, la explicación de esa diferencia sería la crisis demográfica. La gente nacida entre 1532 y 1555 tendría que tener entre 18 y 41 años en 1573, pero, como lo sugiere el cuadro, la natalidad se redujo en dichos años, o muchos que alcanzaron a nacer murieron de niños.

\section{Atenuando las cifras de la catástrofe}

El cuadro general de la evolución de tributarios que mostramos a continuación (Cuadro 6) expresaría que, después de la fuerte caída inicial, hubo una estabilización demográfica hasta mediados de la década de 1580 , cuando la caída volvió a arreciar, al menos hasta 1620 , en que habría comenzado una nueva y lenta era de estabilización.
Historiadores como Nicolás SánchezAlbornoz (1978) cuestionaron que de la disminución del número de tributarios pudiera derivarse un movimiento paralelo en el total demográfico. Los recuentos de las autoridades españoles se concentraban en los indios varones entre 18 y 50 años, que eran quienes pagaban tributo y estaban obligados a cumplir con las mitas y otras cargas coloniales, aunque complementariamente solían incluir la contabilidad del resto de la población como una forma de control del dato de los tributarios. El argumento de SánchezAlbornoz, seguido por autores como Carlos Sempat Assadourian (1989), Luis Miguel Glave (1989), Karen Powers (1995), Héctor Noejovich (1998) y Ann Wightman (1990), fue que los indios desplegaron estrategias de evasión y elusión fiscal, desapareciendo de la contabilidad de las autoridades. Desafiliándose de sus comunidades étnicas, emigraban a las ciudades de españoles, a otros pueblos indios donde permanecían como "forasteros", o ingresaban dentro de latifundios agropecuarios, donde eran protegidos por terratenientes ávidos de su mano de obra. Las mujeres se mestizaban en los asientos mineros, o aun en los propios pueblos, donde los curas doctrineros, aislados de sus colegas, relajaban su templanza (véase figura 1). El "colapso demográfico" fue en verdad el colapso del sistema "despótico tributario" del virrey Toledo, incapaz de atajar las vías de

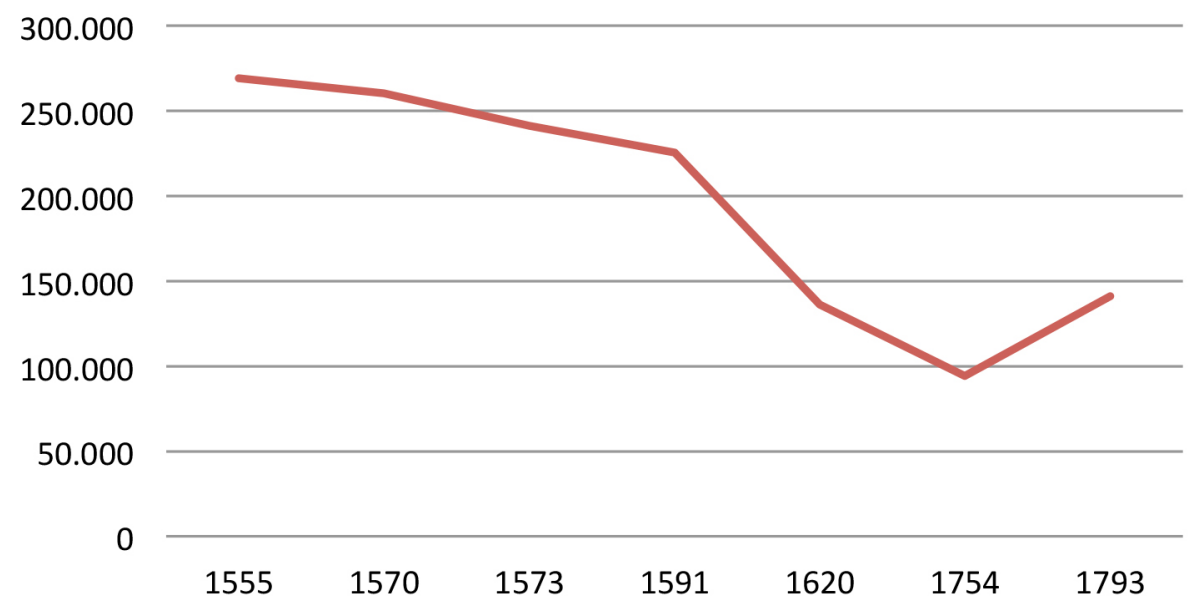

Gráfico 1. Población indígena tributaria en el Perú, 1555-1793.

Fuente: Cuadro 6 (ojo: la escala horizontal no guarda proporción con la distancia entre los años). 
Cuadro 6. Población indígena tributaria en el territorio del Perú actual, 1561-1793.

\begin{tabular}{ccc}
\hline $\begin{array}{c}\text { Fecha aprox. del } \\
\text { recuento }\end{array}$ & Tributarios & Población indígena total \\
\hline 1561 & $269,336^{\circ}$ & $1.164,434$ \\
1570 & 260,544 & $1.290,680$ \\
1573 & 241,046 & \\
1591 & 225,558 & \\
1620 & 136,235 & 671,505 \\
1754 & 94,243 & 401,111 \\
$1793^{\circ}$ & 141,248 & 619.190 \\
\hline
\end{tabular}

${ }^{\circ}$ En este año se consideró tributarios a todos los varones entre los 16 y 50 años, que no fueran caciques o exceptuados. En el resto de años el rango fue de 18 a 50 años.

${ }^{\circ}$ Los datos de 1793 no incluyen a los tributarios y pobladores de Puno, que en ese momento pertenecían al Virreinato del Río de La Plata. Eso sumaría aproximadamente unos 25 mil tributarios y unos ciento treinta mil pobladores indios adicionales, con lo que la tendencia de la recuperación, se acentuaría. Fuentes: Para 1555, Matienzo 1967: 109; para 1570 y 1620: Cook, 2010: 146 y 171; para 1573: Escobedo 1979: 210-264; para 1591: Zavala, 1978-1979, t. I, p. 185; para 1754: Vollmer 1967: 285; para 1793: Unanue 1793.

evasión que una bullente sociedad indígena habría puesto en práctica ${ }^{35}$.

Así, mientras la población indígena descendía aceleradamente, la población de Potosí, el gran centro minero del sur andino, no hacía más que ensanchar y su producción de plata, crecer $^{36}$. El número de indios yanaconas, mingas, forasteros y mostrencos, que eran categorías distintas a las de tributarios, acrecía, conforme se reducía el de estos, por los elevados costos que conllevaba serlo. Sánchez-Albornoz (1978: 26-34) mostró cifras de un conjunto de diez provincias entre 1573 y 1683, en las que, si bien la población indígena total disminuyó en un $42 \%$, la de tributarios cayó más hondamente: un 57\%, mientras que el número de indios adultos (es decir, incluyendo a los varones en edad de tributar, pero exonerados por su condición de "forasteros") se redujo solamente en un $22 \%$. La relación entre el tamaño de la población total y la de tributarios, pasó en dichas provincias entre 1573 y 1683 de 4.65 a 6.28. Sánchez-Albornoz (1978: 27) concluyó que en 1683 hubo una sub numeración de la población femenina, y de niños y ancianos, que escapaban al interés fiscal del Estado, a la vez que un significativo traspaso de indios adultos varones a la categoría de forasteros ${ }^{37}$. Su estimación final fue

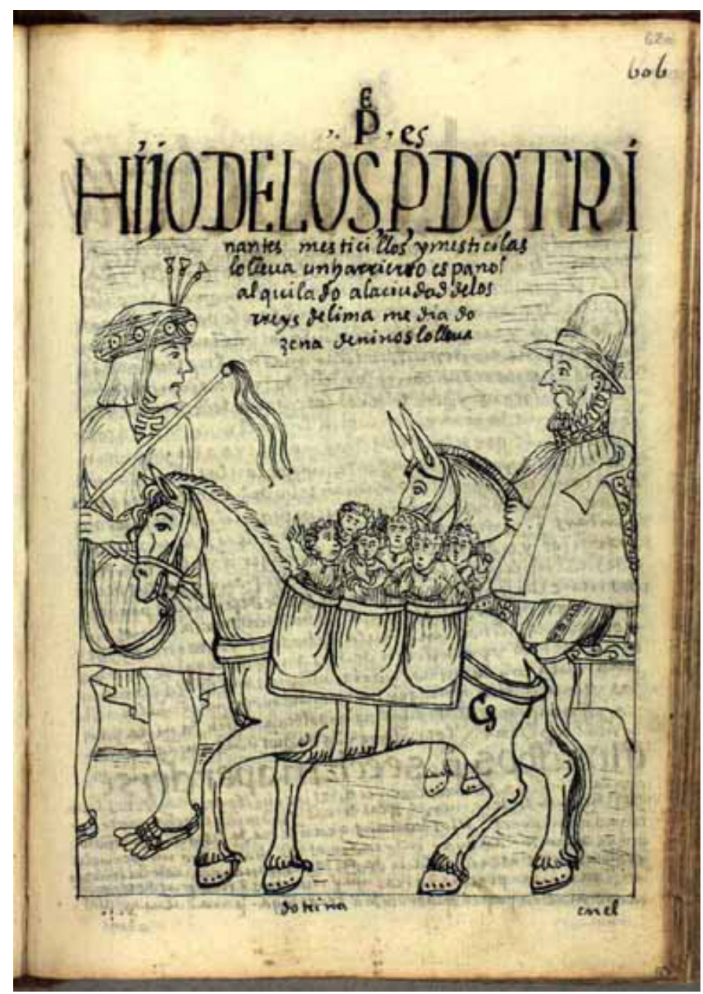

Figura 1. dibujo de la Nueva Corónica y Buen Gobierno de Felipe Huamán Poma de Ayala, 1613, en la que su autor dice: "Padres: hijos de los padres dotrinantes, mesticillos y mesticilas lo lleva un harriero español alquilado a la ciudad de los Reyes de Lima, media dozena de niños lo lleva".

que en el tiempo de La Palata (1683) sobrevivía en la región del sur andino un $40 \%$ de la población indígena presente en vísperas de la conquista, y para 1720, cuando se alcanzó el punto demográfico mínimo, solo un $25 \%$. Si todo el Perú se hubiese comportado como esta región, el tamaño de la población prehispánica no habría superado los dos millones. Sin embargo, parece que la región que, por su importancia fiscal y económica para el gobierno español, cuenta con un volumen de información censal mayor, fue precisamente, siguiendo a Cook, la que mejor sobrellevó la crisis demográfica. Ello, a pesar de que fue esta región la que soportó la presión de las reformas toledanas que impusieron la mita minera y la monetización del tributo ${ }^{38}$.

Concluimos esta parte remarcando que, ni tomando en cuentas las cifras disponibles ni los hechos históricos, hay razón para sostener que durante el lapso de 1532 a 1570 la tasa de despoblación en los Andes haya sido el doble de la que 
tuvo el medio siglo posterior. Si bien una mayor despoblación debió suceder en la fase inicial, entre 1532-1554, no habría ocurrido lo mismo en las siguientes dos décadas, cuando cesaron las guerras y el modo de producción indígena pudo restablecerse al menos parcialmente ${ }^{39}$. La tasa de despoblación del ciclo 1532-1570 debió ser mayor, pero sin alcanzar a doblar la del ciclo 1570-1620. En la primera época, la despoblación fue causada por la guerra de conquista y las epidemias, mientras en la segunda, por nuevas epidemias y la disrupción de la economía indígena provocada por las reducciones, la mita y la monetización del tributo. El tamaño de la población del Perú actual en vísperas del arribo europeo debió rondar los dos y medio millones de habitantes (con un añadido de un millón a un millón y medio más para todo el Tahuantinsuyo), tal como lo propusieron en su día Rosenblat y Kubler.

En cuanto a la cronología de la crisis demográfica peruana, postularíamos tres etapas: a. una de fuerte caída, entre 1530-1555, en la que la población indígena habría descendido de unos 2.5 millones a 1.5 millones, apenas compensada por el arribo de unos pocos miles de colonos españoles y esclavos africanos. La tasa de evolución demográfica durante dicho lapso habría sido de $-2.0 \%$ anual. b. una desaceleración de la crisis entre 1555 y 1585 , en que la población indígena se habría reducido de 1.5 a 1.13 millones $^{40}$, levemente compensada por el crecimiento de una población no indígena, que habría alcanzado unas 70 mil personas para el último año. La tasa de crecimiento durante esta etapa habría sido de $-0.7 \%$ anual ${ }^{41}$. c. Un recrudecimiento de la crisis demográfica entre 1585-1620, cuando la población indígena habría descendido de 1.13 a 0.67 millones, compensada parcialmente por el crecimiento de la población no indígena de españoles, mestizos y africanos, que habrían sumado para el último año unas 180 mil personas ${ }^{42}$. El resultado habría sido una tasa de $-1,0 \%$ anual $^{43}$. Finalmente, vendría una fase de estabilización entre 1620-1720, en que la suma de la población indígena y no indígena se habría mantenido casi estable, pero con una tendencia todavía a la baja, al pasar de unos 850 mil a unos 680 mil habitantes, con una tasa de $-0.2 \%$ por año ${ }^{44}$. Luego de 1720 , pasados los efectos de la epidemia declarada en esa coyuntura, comenzó un ciclo de recuperación. En los años finales del siglo XVIII la población peruana reunía más o menos 1.25 millones, como en los tiempos de Toledo (ver gráfico 2$)^{45}$.

Tomando en cuenta las nuevas cifras sobre la población del México prehispánico propuestas por autores como Andrés Calderón (2017), tendríamos que la caída demográfica inicial en el Perú habría sido mayor que en México, pero que en el período final del siglo XVI habría sido, en cambio, menor. La diferencia en el período inicial pudo obedecer a una mayor resistencia a la conquista por parte de sucesores de la corona inca, como Manco Inca, quien entre 1536-1542 dirigió una furiosa contraofensiva contra los españoles, y a las exploraciones hacia las tierras amazónicas y el sur del continente que organizaron los conquistadores, reclutando miles de nativos. En el período de finales del siglo XVI la mayor devastación demográfica en México pudo tener que ver con un mayor impacto de las epidemias en

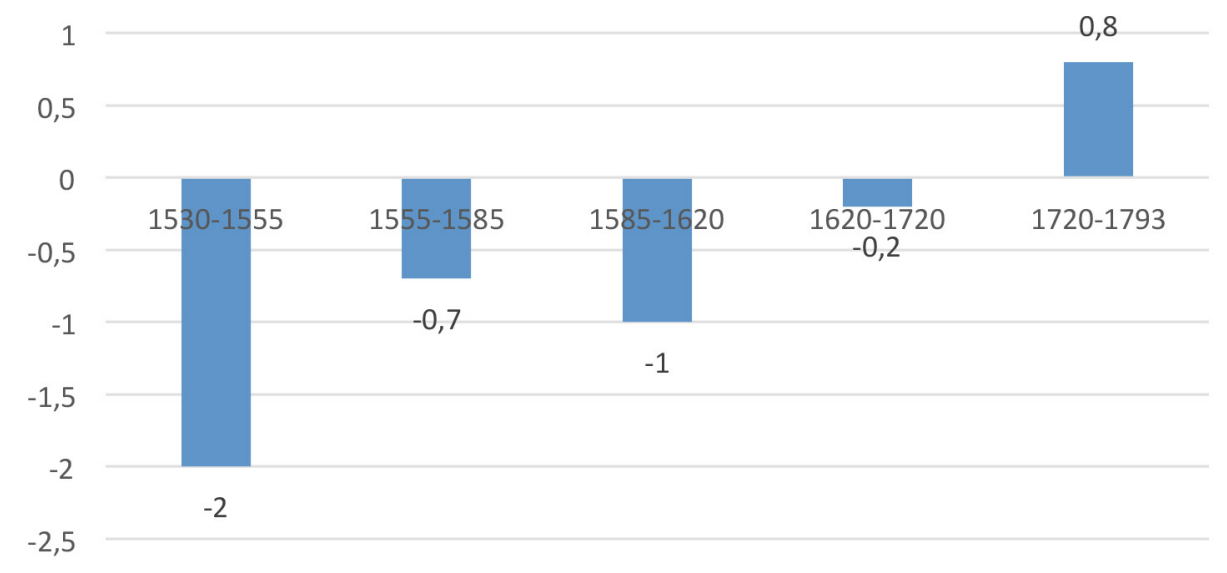

Gráfico 2. Tasas de crecimiento demográfico anual en el Perú, 1530-1793. 
este país, debido a la mayor concentración de su población ${ }^{46}$.

La hipótesis de Polo de Ondegardo, que decía que lo que mataba a los indios era la falta de orden, devenida del colapso del Estado Inca y de sus propios deseos de escapar de las Visitas y retasas, merece cierta atención. La desaparición del Estado Inca desorganizó el sistema de trabajos colectivos, mientras que el afán de eludir una mayor tributación condujo a los indios, de acuerdo a Polo, a destruir sus propias sementeras y pueblos:

"[...] más daño reciben con una novedad, acudiendo a su condición, que con la mitad de tributo que se les subiese. Y en tratando de visitallos para entender lo que tienen y pueden, son tantas las diligencias que hacen para encubrillo, ques el daño irrecuperable. Y finalmente quando lo toman a pechos, como lo hacen, ni queda pueblo que no asuelen ni sementera que no arranquen con esta pretensión. Y finalmente de una visita quedan más destruidos que de diez años que diesen doblada tassa, y en estos términos están agora" (Polo 2013: 310, párrafo 658).

El fino observador que fue Polo, mencionó que la desesperación de los indios por la situación que vivieron durante la conquista y asentamiento español, los llevó incluso al suicidio:

"Y es lo peor que [los indios] se quedan así en lugares, que después ni pueden ser doctrinados, ni hallados para administrarles los sacramentos. Y aún yo he visto ahorcados algunos, porque aún que con aquel ímpetu que se les manda lo ponen por ejecución con gran prisa y voluntad; después, cuando se hallan sin su hato y lo hallan perdido, ayuda el demonio a sus imaginaciones y fáltales la consideración. Y así se pierden, y aún gente principal, y queda desbaratada su orden"47.

Polo escribía desde un pensamiento que suponía que el orden político y la diligencia en el trabajo mejoraban la salud y alargaban la vida. Acusa que a los indios el tiempo comenzó a sobrarles con las nuevas tasas dictadas por La Gasca, que disminuyeron sensiblemente el tiempo de trabajo necesario para cumplir con sus tasas:
"De manera que el tributo agora es mucho menos porque lo es el trabajo que pasan en darle, lo qual está provado por el mucho tienpo que les sobra, mediante el qual y sus vicios se acaban muchos, [...]" (Polo 2013: 292, párrafo 581).

\section{Las consecuencias económicas de la crisis demográfica}

El argumento de este trabajo ha sido hasta aquí aminorar las dimensiones de la crisis demográfica andina, pero no cabe duda de que esta existió y que, incluso si "solo" implicó la disminución de la población a una cuarta parte (en vez de a una décima parte, como algunos sostienen) un siglo después del arribo español, la caída fue grave y de hondas consecuencias; más todavía, porque se detuvo recién dos siglos después. Hubo que esperar hasta la segunda mitad del siglo XIX para que el país recuperase el volumen de población previo a la conquista y la "falta de brazos" fue una queja frecuente de los empresarios agrarios y mineros del país hasta los inicios del siglo XX.

La crisis demográfica cambió los precios relativos de la tierra y el trabajo. Aquella se volvió abundante y este, en cambio, escaso y apreciado. La escasez de mano de obra indígena condujo a la importación de esclavos africanos entre los siglos XVI-XVIII y a la de trabajadores asiáticos en el siglo XIX, así como a la instauración de formas de trabajo forzado, como fue la mita. Cuando el trabajo de los hombres se vuelve muy costoso, un efecto perverso es que para quienes van a aprovecharlo sale a cuenta volverlo trabajo forzado. El valor que alcanzó el trabajo indígena fue tal, que compensó encarar los costos de controlar a los indios en sus pueblos (y hacerlos construir nuevos pueblos), con tal de poder aprovechar su mano de obra. El establecimiento de las reducciones a partir del Gobierno de Toledo, buscó controlar más cercanamente ese bien preciado en que se iba convirtiendo el trabajo indígena, al concentrar a esta población en pueblos de unas quinientas familias, donde pudiesen ser visitados por las autoridades (Lohmann y Saravia 1986-1989, Saito y Rosas 2017).

Tales esfuerzos dieron resultados solamente parciales. Paralelamente al fenómeno de la despoblación indígena ocurrió la aparición de "yanaconas" y "forasteros", quienes eran pobladores 
indígenas que escapaban de sus antiguas o nuevas unidades sociales (ayllus o reducciones) para insertarse en condiciones más libres en el naciente mercado de trabajo. Tanto Luis Capoche (1959: 173-174) para Potosí, como López de Caravantes (1985) para Huancavelica, dieron cuenta del incremento de los salarios en las minas (véase Cuadro 7). Para 1630 los salarios en Huancavelica doblaban los de medio siglo atrás. El incremento ocurría no solo en la remuneración monetaria, cuanto en el horario de la labor, la entrega de coca o comestibles y el derecho a quedarse con parte de los minerales que extraían. En algunos casos los trabajadores terminaron convertidos en una suerte de socios del empresario minero ${ }^{48}$. Para las minas de Potosí, García de Llanos y López de Caravantes (1985, I: 103) registraron jornales de 8 reales (un peso) para las primeras décadas del siglo XVII en el caso de los trabajadores libres ${ }^{49}$.

Disciplinar a la mano de obra se convirtió en una operación difícil en un escenario de escasez laboral, lo que propició que tratara de hacerse apelando a mecanismos políticos antes que económicos. Los estudios sobre las condiciones laborales en las minas de Potosí y Oruro refieren las maniobras que los corregidores, mandones y mayordomos de minas, y caciques hacían para aprovechar y abaratar el trabajo indígena ${ }^{50}$. La falta de derechos sociales y políticos de los indios hizo que estos no pudieran sacar fácilmente partido del aprecio que había ganado su mano de obra, atrayendo en cambio contra ellos los afanes de dichos personajes.

Los datos para el sector agrario son más escasos. Para la región de Arequipa, Keith Davies (1974: 59-60) rastreó contratos de trabajo a lo largo del siglo XVII. Para 1596 un contrato típico implicaba una remuneración anual de doce pesos, más un topo de tierra (aproximadamente un tercio de hectárea) de cultivo y medicinas en caso de

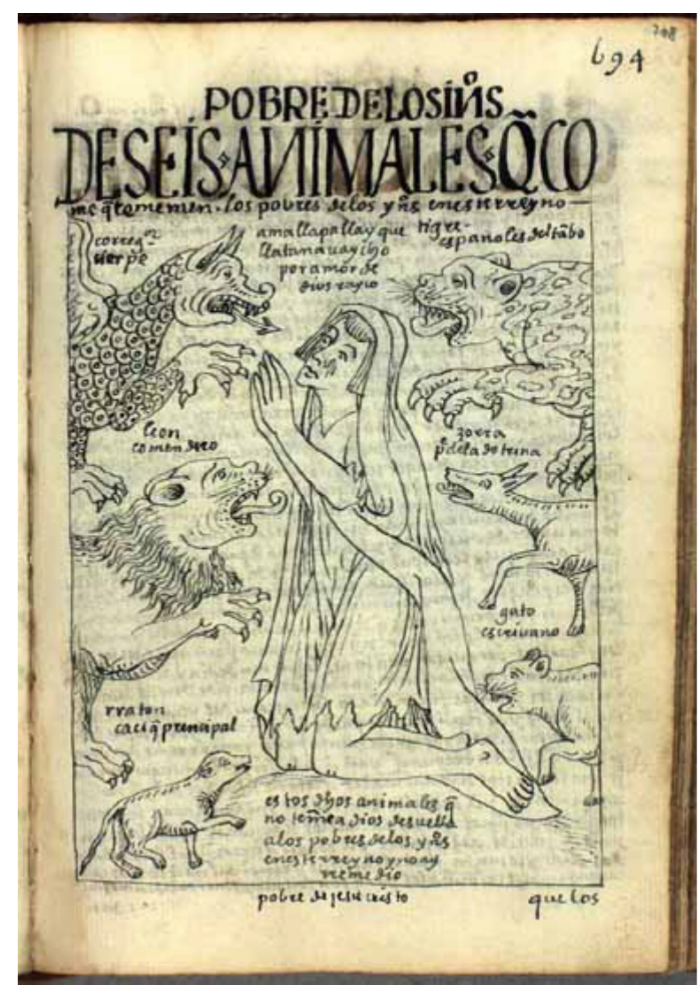

Figura 2. Huamán Poma de Ayala, 1613: "Pobres de los indios. De seis animales que come que tememen (sic) los pobres de los indios en este reino. Estos dichos animales que no temen a Dios desuellan a los pobres de los indios y no hay remedio. Pobre de Jesucristo".

enfermedad, mientras que para 1657 la remuneración implicaba los mismos doce pesos, más dos piezas de ropa de abasca, y semanalmente media fanega de maíz y dos reales para carne.

El aumento del valor del trabajo fue aprovechado, en el caso de la población nativa que permaneció encuadrada dentro de las reducciones o comunidades indígenas, por los intermediarios que existían entre ella y los empresarios, como los corregidores, encomenderos y caciques. El dibujo de Huamán Poma en que aparece un

Cuadro 7. Salarios en el asiento minero de Huancavelica.

\begin{tabular}{|c|c|c|}
\hline Años & Jornal de mitayos & Fuente \\
\hline 1573 & 1 real y 1 tomín + alimentos & Lohmann 1949: 104-05 \\
\hline 1573 & $1 \frac{1}{4} \mathrm{real}+$ alimentos & López de Caravantes, 1985, IV, 139 \\
\hline 1590 & $2 \frac{1}{2}$ reales +1 real por $\mathrm{c} / 6$ leguas de viaje & Lohmann 1949: 173 \\
\hline 1630 & 3 reales ( $21 / 2$ en plata y $1 / 2$ en granos) & López de Caravantes, 1985, II, 77 \\
\hline 1630 & $31 / 2$ reales & Lohmann 1949: 305 \\
\hline 1680 & $31 / 2$ reales. Trabajadores libres: entre 8 y 12 reales & Lohmann 1949: 382, 423 \\
\hline
\end{tabular}


indio rodeado de una jauría de animales que lo "desuellan", y representan al encomendero, el corregidor, el párroco de la doctrina y el cacique principal, es expresivo del acoso que los observadores percibían sobre los indios para aprovecharse de su trabajo (ver figura 2).

Para atraer mano de obra a sus latifundios, los terratenientes debieron ofrecer el usufructo de tierras y protección política, por lo que se instauró el régimen del colonato o yanaconaje, que se prolongaría hasta mediados del siglo XX, cuando entró en crisis, a raíz de la explosión demográfica ocurrida en dicha centuria, que volvió a invertir los valores relativos de la tierra y el trabajo (Caballero 1981). Las mejoras salariales y el derecho a quedarse con parte de lo producido, que obtuvieron los trabajadores durante el largo ciclo de escasez laboral, se transformaron, sin embargo, poco en poder político y capital social.

De otro lado, a raíz de la crisis demográfica la economía peruana de la segunda mitad del siglo XVI se vio presionada a abandonar el modelo centrado en la encomienda y en el aprovechamiento del excedente producido por la economía campesina indígena. Abundante de recursos naturales pero escasa de trabajo, la economía debió desarrollar actividades productivas que, haciendo uso copioso del recurso natural, insumiesen poca mano de obra. La minería fue una de estas actividades y, así, el declive de la población indígena fue paralelo al crecimiento de la producción de plata ${ }^{51}$. No fue el trabajo minero la causa de la crisis demográfica, como se postuló en el pasado, sino al revés: la crisis demográfica condujo a la minería. Reducida la población a menos de un millón de habitantes, dispersos en un territorio difícil de comunicar y pobres de ingresos en su mayor parte, la producción fue orientada a satisfacer la demanda del mercado externo. La vocación por la minería de exportación se constituyó desde ahí en una marca persistente de la economía de los países andinos.

\section{Agradecimientos}

Agradezco los comentarios recibidos de los árbitros anónimos de este artículo.

\section{Referencias Citadas}

Acemoglu, Daron, Simon Johnson y James Robinson

2002 "Reversal of Fortune: Geography and Institutions in the Making of the Modern World Income Distribution". Quartely Journal of Economics No 118; pp. 1231-1294.

Arroyo, Leticia, Elwyn Davies y Jan Luiten van Zanden 2012 "Between Conquest and Independence: Real Wages and Demographic Change in Spanish America, 15301820". Explorations in Economic History $\mathrm{N}^{\circ}$ 49:2; pp. 149-166.

Assadourian, Carlos S.

1985 "La crisis demográfica del siglo XVI y la transición del Tawantinsuyu al sistema mercantil colonial". En Nicolás Sánchez-Albornoz, comp., Población y mano de obra en América Latina. Pp. 69-93. Madrid: Alianza América.

1989 "La despoblación indígena en Perú y Nueva España durante el siglo XVI y la formación de la economía colonial. Historia Mexicana XXXVIII:3; pp. 419-453. México: El Colegio de México.

1994 Transiciones hacia el sistema colonial andino. Lima/ México: Instituto de Estudios y El Colegio de México.

Baudin, Louis

1943 (1928) El imperio socialista de los Incas. Santiago de Chile: Zigzag, 1943.

Borah, Woodrow y Sherburne Cook

1963 The Aboriginal Population of Central Mexico on the Eve of the Spanish Conquest. Berkeley: University of California Press.

Brown, Kendall

2015 Minería e imperio en Hispanoamérica colonial. Producción, mercados y trabajo. Lima: BCRP-IEP.
Caballero, José M.

1981 La economía agraria de la sierra peruana, antes de la reforma agraria de 1969. Lima: IEP.

Calderón Fernández, Andrés

2017 Mirando a Nueva España en otros espejos. Cuatro ensayos sobre demografía y niveles de vida. Tesis doctoral, Universidad Complutense de Madrid.

Capoche, Luis

1959 Relación general de la Villa Imperial de Potosí (1585). Ed. de Lewis Hanke. Madrid: Biblioteca de Autores Españoles.

Carrió de la Bandera, Alonso (Concolorcorvo)

1973 (1773) Lazarillo de ciegos caminantes. Ed. de Emilio Carilla. Barcelona: Labor.

Chocano, Magdalena

2006 "La evolución de la población y los nuevos perfiles demográficos de una región andina: Conchucos, 15431940". Revista Andina No 43. Cuzco: Centro de Estudios Andinos Bartolomé de Las Casas, pp. 129-159.

Contreras, Carlos

1995 Los mineros y el rey. Los Andes del norte: Hualgayoc 1770-1825. Lima: IEP.

Cook, Noble David

1965 La población indígena del Perú colonial. Rosario: 1965.

ed., 1975 Tasa de la Visita General de Francisco de Toledo. Lima: Universidad Nacional Mayor de San Marcos.

1981 Demographic Collapse: Indian Peru 1520-1620. Cambridge: Cambridge University Press. 
1982 "Population Data for Indian Peru: Sixttenth and Seventeenth Centuries". Hispanic American Historical Review 62:1; 73-120.

2010 La catástrofe demográfica andina. Perú 1520-1620. Lima: Fondo Editorial de la PUCP.

Davies, Keith

1974 The Rural Domain of the City of Arequipa. U. de Michigan: Tesis de doctorado.

Dell, Melisa

2011 "Los efectos persistentes de la mita minera en el Perú". Apuntes N$^{\circ}$ 68; pp. 211-265. Lima: Universidad del Pacífico, 2011.

Denevan, William, ed.

1992 The Native Population of the Americas in 1492. 2da ed. Madison: University of Wisconsin Press.

Dobado González, Rafael

2009 "Herencia colonial y desarrollo económico en Iberoamérica: una crítica a la "nueva ortodoxia". En Enrique Llopis y Carlos Marichal, coords., Latinoamérica y España, 1800-1850. Un crecimiento económico nada excepcional. Pp. 253-292. Madrid y México: Marcial Pons e Instituto Mora.

Dobyns, Henry

1966 "Estimating Aboriginal American Population: An Appraisal of Techniques with a New Hemisphere Estimate". En Current Antropology N No 7; pp. 395-449.

Engerman, Stanley y Kenneth Sokoloff

1999 "Dotación de factores, instituciones y vías de crecimiento diferentes entre las economías del Nuevo Mundo. Una vision de historiadores de economía estadunidenses". En Stephen Haber, comp., Cómo se rezagó la América Latina. Ensayos sobre las historias económicas de Brasil y México, 1800-1914. Pp. 305-357. México: FCE.

Escobedo, Ronald

1979 El tributo indígena en el Perú (siglos XVI-XVII). Pamplona: Ediciones de la Universidad de Navarra.

Gavira, María Concepción

2005 Historia de una crisis: la minería en Oruro a fines del período colonial. La Paz: Instituto de Estudios Bolivianos, Instituto Francés de Estudios Andinos y Universidad Michoacana de San Nicolás Hidalgo, 2005.

2009 "Las condiciones laborales de los trabajadores mineros de Charcas y Michoacán a fines del siglo XVIII". En Enriqueta Quiroz y Diana Bonet, coords., Condiciones de vida y trabajo en la América colonial: legislación, prácticas laborales y sistemas salariales. Bogotá: Universidad de los Andes, 2009.

Glave, Luis M.

1989 Trajinantes. Caminos indígenas en la sociedad colonial, siglos XVI-XVII. Lima: Instituto de Apoyo Agrario.

Huamán Poma de Ayala, Felipe

1983 (1613) Nueva Corónica y Buen Gobierno. 2 vols. Ed. De Franklin Pease. Caracas: Biblioteca Ayacucho.

Kroeber, Alfred

1934 "Native American Population". The American Antropologist Vol. XXXVI. N. York.

Kubler, George

1946 "The Quechua in the Colonial World". En Julian Steward, ed., Handbook of South American Studies; pp. 331-410. Washington D.C., 1946.

Livi Bacci, Massimo

(2006-a) "The Depopulation of Hispanic America after the Conquest". Population and Development 32:2; pp. 199-232. (2006b) Los estragos de la conquista. Quebranto y declive de los indios de América. Barcelona: Crítica.

Lockhart, James

1982 El mundo hispano peruano, 1532-1560. México: FCE.

Lohmann, Guillermo y María Justina Saravia, eds.

1986-1989 Francisco de Toledo: disposiciones gubernativas para el virreinato del Perú. 2 ts. Sevilla: Escuela de Estudios Hispanoamericanos.

López de Caravantes, Francisco

1985 (1632) Noticia general del Perú, 6 ts. Madrid: Atlas.

Macera, Pablo y Alejandro Arancibia

1972 "Aspectos históricos. Demografía y población en el Perú". En Centro de Estudios de Población y Desarrollo, Informe demográfico: Perú 1970. Lima: CEPD, pp. 3-17.

Matienzo, Juan de

1967 [1567] Gobierno del Perú. Edición y Estudio Preliminar de Guillermo Lohmann Villena. París.

Means, Philip

1932 Fall of the Inca Empire and the Spanish Rule in Peru, 1530-1720. Nueva York: Charles Scriber's Sons.

Merluzzi, Manfredi

2014 Gobernando los Andes. Francisco de Toledo, virrey del Perú, 1569-1581. Lima/Roma: PUCP/Universitá degli Stufdi.

Murra, John V., ed.

1967-1972 Visita de la provincia de León de Huánuco (1562). 2 vols. Huánuco: Universidad Nacional Hermilio Valdizán.

2002 El mundo andino. Población, medio ambiente y economía. Lima: IEP-PUCP.

Noejovich, Héctor

1998 "Demografía histórica y tributo indígena: aportes críticos". En Actas del IV Congreso Internacional de Etnohistoria. 3 vols. Lima: PUCP.

Noejovich. Héctor y Estela Salles

2008 La "Visita general" y el proyecto de gobernabilidad del virrey Toledo: Yndice del Reparttimientto de Tazas de las Provincias conttenidas en este libro hechas en tiempo del Excmo ..... Lima: Universidad San Martín de Porres.

Noli, Estela

2017 Revisitando Ibatín, investigaciones históricas y arqueológicas. Tucumán: Universidad Nacional de Tucumán, 2017.

Pearse, Adrian

2005 "El censo demográfico peruano, 1725-1740". En Paulo Drinot y Leo Garofalo, eds., Mas allá de la dominación y la resistencia. Lima: IEP.

Pease, Franklin

1991 Los Incas. Lima: Fondo Editorial de la PUCP.

Polo de Ondegardo, Juan

2013 [1561-1571] El orden Inca, por el Licenciado Polo de Ondegardo. Ed. de Andrés Chirinos y Martha Zegarra. Lima: Editorial Commentarios SAC.

Powers, Karen

1995 Andean Journeys: Migrations, Ethnogenesis and the State in Colonial Quito. Albuquerque: University of New Mexico Press.

Quiroga, Pedro de

1992 [c. 1568] Coloquios de la Verdad, Ed. de Daisy Rípodas Ardanaz. Valladolid: Instituto de Cooperación Iberoamericana y Casa Museo de Colón y Seminario Americanista. 
Rosenblat, Angel

1954 La población indígena y el mestizaje en América. 2 vols. Buenos Aires: Nova, 1954.

1967 La población de América en 1492: viejos y nuevos cálculos. México: El Colegio de México.

Rostworowski, María y Pilar Remy, eds.

1992 Las Visitas de Cajamarca. 2 ts. Lima: IEP.

Rowe, John

1946 "Culture at the Time of the Spanish Conquest". En Julian Steward, ed., Handbook of South American Studies; pp. 183-330. Washington D.C., 1946.

Saito, Akira y Claudia Rosas, eds.

2017 Reducciones: la concentración forzadas de las poblaciones indígenas en el Virreinato del Perú. Lima: Pontificia Universidad Católica del Perú y National Museum of Etnology of Japan.

Sánchez-Albornoz, Nicolás

1978 Indios y tributos en el Alto Perú. Lima: IEP.

2014 La población de América Latina. 3ra ed. México: El Colegio de México.

Seminario, Bruno y Nikolai Alva

2012 "El PBI, tres siglos pasados y media centuria venidera". En Bruno Seminario, Cynthia Sanborn y Nikolai Alva, eds., Cuando despertemos en el 2062. Lima: Universidad del Pacífico.

Smith, C. T.

1970 "Depopulation of the Central Andes in the 16th Century”. En Current Antropology No 11; pp. 453-464.

Stern, Steve

1986 Los pueblos indígenas del Perú y el desafío de la conquista española. Huamanga hasta 1640. Madrid: Alianza América.

Tantaleán, Javier

2002 "Choque de civilizaciones: ¿Eclipse demográfico en los Andes y la selva, ocaso de la costa (siglo XVI)?". En Pirú. Espacio, economía y poder (12,000 a.C.-1572 d.C.), 3 ts. T. III: 1121-1174. Lima: Fondo Editorial del Congreso del Perú.
Unanue, Hipólito

1793 Guía Política, Eclesiástica y Militar del Perú para el año de 1793. Lima: Sociedad Amantes del País.

Valcárcel, Luis Eduardo

1959 Etnohistoria del Perú antiguo. Lima: Universidad Nacional Mayor de San Marcos.

Vásquez de Espinoza, Antonio

1948 Compendio y descripción de las Indias Occidentales. Washington: Smithsonian Institution.

Vollmer, Gunther

1967 Bevölkerungspolitik und Bevölkkerungestruktur im Vizeköniigreich Peru zu Ende der Kolonial zeit (17411821). Colonia.

Wachtel, Nathan

1976 (1971, La visión des vaincus). Los vencidos. Los indios del Perú frente a la conquista española (15301570). Madrid: Alianza Editorial.

Wightman, Ann

1990 Indigenous, migration and social change: the forasteros of Cuzco, 1570-1720. Durham: Duke University Press.

Zagalsky, Paula

2017 "Trabajo indígena, conflictos y justicia en la Villa Imperial de Potosí y su Cerro Rico, una aproximación. Virreinato del Perú, siglos XVI-XVII". En Revista Historia y Justicia N$^{\circ}$ 9. Santiago de Chile: 2017.

2014 "Trabajadores indígenas mineros en el Cerro Rico de Potosí: tras los rastros de sus prácticas laborales (siglos XVI y XVII)". En Revista Mundos do Trabalho $\mathrm{N}^{\circ} 6: 12$, pp. 55-82. Salvador de Bahía, 2014.

Zavala, Silvio

1978-1979 El servicio personal de los indios en el Perú, 3ts. México: El Colegio de México.

Zuloaga, Marina

2012 La conquista negociada. Guarangas, autoridades locales e imperio en Huaylas, Perú (1532-1610). Lima: IEP/IFEA.

\section{Notas}

Ver Denevan 1992.

Ver, por ejemplo, Livi 2006b y Calderón Fernández 2017

Cook 1981, 2010, Tantaleán 1998.

En los años treinta hubo intentos previos de Alfred Kroeber (1934) y Philip Means (1932) en los Estados Unidos; en el siglo XIX historiadores como el padre Ricardo Cappa y Sebastián Lorente, y viajeros como Ephraim G. Squier, propusieron como población del Tahuantinsuyo cantidades de cuatro y diez millones, respectivamente. De acuerdo a Pablo Macera y Alejandro Arancibia (1972) el intento más antiguo fue el de Alonso Carrió de la Vandera (Concolorcorvo) en 1773, quien propuso la cifra de siete millones. Sobre la historia de estos cálculos ver Cook (1965) y Tantaleán (2002).

5 Rosenblat (1954) sugirió como poblaciones prehispánicas de Perú, Ecuador y Bolivia, las cifras de dos millones, quinientos mil y ochocientos mil, respectivamente, que sumadas darían los 3.3 millones.

$6 \quad$ El propio Cook (1975) publicó una de estas fuentes: la Tasa de la Visita General de Francisco de Toledo.
7 Cook, 2010, pp. 165 y 171. Las siguientes referencias a los planteamientos de Cook se referirán a esta misma obra.

8 Livi Bacci (2006-a: 214) califica de débil la probabilidad de que Huayna Cápac haya muerto por una epidemia europea, y que estas epidemias hayan precedido a los conquistadores.

9 Woodrow Borah y Sherburne Cook (1963) fueron quienes propusieron la cifra de 25 millones para la zona central de México. Puede verse una crítica a su propuesta en Rosenblat, 1967. Pueden verse estimaciones más recientes en la nueva edición del clásico libro de Sánchez-Albornoz (2014: 58-59) La población de América Latina, así como en Calderón Fernández 2017.

10 Dice Assadourian (1985: 77): "Nuestra impresión es que durante el período semisecular de 1550-1600 hubo una continuidad en el proceso de despoblación, pero con tasas bajas comparadas con las que rigieron durante la fase que concluye hacia 1550.".

11 Lockhart (1982: 292) refiere una población máxima de cinco mil a diez mil españoles para 1560, "fuertemente 
concentrada en las ciudades". Las "entradas" y exploraciones de los conquistadores se hicieron sobre territorios relativamente poco poblados, como la Amazonía o Chile.

12 "Durante las primeras cuatro décadas del dominio europeo no hubo acciones realmente efectivas contra las formas de acceso de las unidades domésticas al medio de producción tierra; tampoco parece haber ocurrido una alteración sustantiva en los patrones andinos de ocupación del suelo." (Assadourian, 1985: 84).

13 Los textos de Juan Polo de Ondegardo (2013), de 1561 (conocido como "Informe al Licenciado Briviesca con las Respuestas a la Instrucción del Rey) y 1571 ("Relación de los fundamentos acerca del notable daño que resulta de no guardar a los indios sus fueros", abonan también en favor de esta idea.

14 Zuloaga, 2012; Merluzzi, 2014; Assadourian, 1994, "Piedad cristiana y desconstrucción".

15 La más rica y conocida de estas informaciones es la Visita de Huánuco, publicada entre 1967-1972 por Murra.

16 Existe también una edición, aún incompleta, de Noejovich y Salles, eds., 2008.

17 El virrey Hurtado de Mendoza señaló que en la preparación de la Relación de tributarios "[...] se ha gastado harto tiempo y puesto no poco trabajo." Citado por Escobedo, 1979: 165.

18 Juan de Matienzo (1967: 109) reproduce los datos de Avendaño bajo el título de "Relación de los naturales que hay en los repartimientos en este Reino del Perú, de todas edades, de los tributarios que pareció haber por la última visita que de ellos se hizo por orden del Marqués de Cañete, y del valor de los tributos en que están tasados hasta el año de 1561 ".

19 Para el caso de Tucumán, ver Estela Noli (2017). Agradezco la referencia a Gabriela Tío Vallejo.

20 Para el cálculo hemos tomado como dentro del Perú, la mitad del distrito de La Paz, tanto para la población total como para la de tributarios.

21 N. Wachtel (1976: 138 y ss.) trabajó para sus cálculos demográficos básicamente con los datos de 1561 y 1591 , pero para la fecha más temprana usó el medio millón de tributarios calculados por Matienzo, asumiendo una población total de 2.5 millones para 1560 , y entre 1.3 y 1.5 millones para 1590 , con un porcentaje de despoblación entre ambas fechas de aproximadamente $40 \%$ y un $1.7 \%$ de caída anual.

22 Acerca de los indios en el centro minero de Potosí, señaló que "Están allí muy sanos e sin ninguna enfermedad, y cuando la tienen son muy bien curados. Procrean muchos hixos, en tal abundancia, que no hay muger que no para cada año, y ansi trae uno en brazos, otro de la mano y otro en la barriga, que es cosa de ver porque en ninguna parte del Reino procrean más que allí." (Matienzo 1967: 29).

23 De Polo (2013), véase por ejemplo: Informe al Licenciado Bibriesca, o Respuesta a la Ynstrucción del Rey; p. 312, párrafo 669. Por su parte, Pedro de Quiroga (1992: 102) señaló en sus Coloquios de la Verdad, lo siguiente: “¡Oh, si supieseis, cristianos, las tiranías que pasan entre nosotros, los indios, los robos e insultos que nos hacemos los unos a los otros, los homicidios, las fuerzas que pasan sin ley y sin castigo y sin justicia que nos lo estorba! ¿Pues qué diré de las tiranías de nuestros caciques y de lo que hace de nosotros, como no ven Inca ni Rey que se lo demande? Quede esto aquí tocado solamente, que adelante yo te contaré estos casos, aunque no sin lágrimas."
24 Cook, 2010: 146 y 158. Cook presenta en un anexo los datos demográficos recogidos para los distintos repartimientos, pero no los agrega según provincias ni presenta un total de la Visita. Puede presumirse, sin embargo, que el dato de tributarios que da para 1570 en diversos cuadros $(260,544)$ es el que resulta de la suma de la Visita de Toledo.

25 Escobedo 1979: 210-264. En el caso de la provincia de $\mathrm{La} \mathrm{Paz}$, he sumado los datos de los repartimientos correspondientes al Perú actual.

26 También podría pensarse que no hubo solicitudes de retasa porque en dichas regiones los Protectores de indios fueron menos celosos de su ministerio que en las provincias donde sí hubo retasa, pero ya es llevar la especulación con un sesgo.

27 Cook (1975: XXVIII-XLIII) presentó en su edición de la Tasa de Toledo, datos que al sumarlos difieren, por lo general levemente, de los datos que resultan al operar con las cifras de Escobedo. Según los datos de Cook, Huamanga tendría 22,160 tributarios, Arequipa, 23,586, Cuzco, 79,919, La Paz, 26,502 y Charcas, 30,275. Hemos preferido trabajar con las cifras de Escobedo, porque incorporan el resumen existente acerca de las regiones del norte peruano.

28 El incremento del tributo pudo tener que ver con el auge minero de Potosí, iniciado hacia 1575.

29 Assadourian (1989: 421) anotó ya, prudentemente, que: "Debemos esperar todavía un mejor conocimiento de las características demográficas del arco semisecular 1550-1600".

30 Rostworowski y Remy 1992, pp. 59-60.

31 Cook (2010: 346) da la cifra de 2678 tributarios para Cajamarca en 1575, mientras Escobedo (1979: 261) da la cifra de 9290. Ambos se basaron en la Visita de Toledo en el Archivo General de Indias, pero Cook da la referencia de la sección Escribanía de Cámara, mientras Escobedo, el fondo Contaduría.

32 Ver Chocano, 2006.

33 Escobedo 1979: 86. Cita este autor que López de Caravantes, de quien tomó los datos, mencionó como causa de la disminución "la encubierta que tenían los caciques ..." para evitar la mita de Huancavelica.

34 Cook, 2010, p. 368. La edición en castellano del libro de Cook trae varios casos similares; ver por ejemplo los de los Chupachos y Conchucos, unas páginas más atrás.

35 Noejovich 1998

36 Sobre los factores de atracción y las condiciones de trabajo en Potosí, véase Arroyo, Davies y Van Zanden 2012 y Zagalsky 2014.

37 Hay que reconocer que Cook no deriva aritméticamente la población total del número de tributarios y que es muy consciente de que la relación entre tributarios y población indígena total puede ser muy cambiante según las épocas y regiones. Pero confió, como Polo de Ondegardo, en que los funcionarios coloniales conocían estas prácticas y tomaban medidas para no dejarse embaucar. "Mi posición en lo que respecta a este punto fue que si bien la población de forasteros creció, los funcionarios los contaban y empadronaban, de modo que ellos quedaron incluidos en muchos de los primeros censos." (Cook 2010: 25).

38 Assadourian 1985: 91. Ver asimismo el estudio de Melisa Dell (2011), quien encontró una correlación entre la pobreza de hoy y las expoliaciones coloniales de ayer. 
39 Véase sobre ello Stern 1986 y Zuloaga 2012.

40 La cifra de 1.13 millones para 1585 la obtenemos multiplicando por cinco el número de tributarios registrado en la Relación de Morales de Figueroa.

41 Hasta aquí coincidimos con Assadourian (1985: 77) cuando señala: "Nuestra impresión es que durante el período semisecular de 1550-1600 hubo una continuidad en el proceso de despoblación, pero con tasas bajas comparadas con las que rigieron durante la fase que concluye hacia 1550."

42 El Compendio de Vásquez de Espinoza (1948) registró 16,850 vecinos "españoles" en el Perú, que, añadidos los familiares dependientes, resultarían en una cifra de cien mil habitantes urbanos. A esta cantidad habría que añadir a los españoles, mestizos y esclavos rurales.

43 Si omitiéramos a la población no indígena, la caída sería mayor, alcanzando el 1,5 anual.

44 Entre los años de 1719-1723 habría ocurrido una severa epidemia en el Perú, que provocó una gran mortandad, especialmente entre la población indígena. Ver Pearse 2005. El dato de 1720 lo hemos tomado de Seminario y Alva 2012: 124.
45 El censo de Gil de Taboada de 1791 dio la cifra de 1.076,997 habitantes. Sumándole la intendencia de Puno, que en 1796 volvió al Perú, redondearía poco más de 1.2 millones.

46 Este es el argumento que da Livi Bacci (2006: 226), quien también hace notar que el hecho de que en el Perú la capital virreinal se ubicase en la costa, relativamente deshabitada de indios tras la crisis inicial, previno un mayor contacto entre indios y españoles en este país.

47 Polo de Ondegardo (2013), "Tratado de un cartapacio a manera de borrador que quedó en los papeles del Licenciado Polo de Ondegardo cerca del linaje de los ingas y cómo conquistaron"; p. 259; párrafo 463.

48 Ver, para el caso de Hualgayoc, nuestro libro (Contreras 1995).

49 Las referencias de García de Llanos han sido recogidas por Zagalsky 2014.

50 Sobre Oruro y Carangas, ver Gavira 2005 y 2008. Para Potosí: Zagalsky 2014 y 2017.

51 Kendall Brown, Minería e imperio en Hispanoamérica colonial. Producción, mercados y trabajo. Lima: BCRPIEP, 2015. 